Martín Sevillano, A.B. (2020): Son ilusiones: identidad cultural en la periferia urbana española desde Los Chichos hasta Estopa. Cultura, Lenguaje y

Representación, Vol. XXIV, 105-121

ISSN $1697-7750 \cdot$ e-ISSN 2340-4981

DOI: http://dx.doi.org/10.6035/clr.2020.24.6

\title{
Son ilusiones: identidad cultural en la periferia urbana española desde Los Chichos hasta Estopa ${ }^{1}$
}

Son ilusiones: cultural identity in the Spanish blue-collar suburbs from Los Chichos to Estopa

ANA BELÉN MARTÍN SEVILLANO

UNIVERSIDAD DE MONTREAL

Artículo recibido el / Article received: 2020-03-30

Artículo aceptado el / Article accepted: 2020-07-25

RESUMEN: La producción cultural de la clase obrera española ha recibido escaso reconocimiento histórico en España, país que presenta un modelo social que liga las prácticas artísticas a las clases media y alta. A partir de 2011, tras el movimiento político $15 \mathrm{M}$, la crítica ha iniciado un tímido proceso de recuperación y revalorización de prácticas culturales que han sido consideradas de mal gusto o marginales en virtud del origen social de sus artífices y de su audiencia. La rumba suburbana de Los Chichos y Estopa es un ejemplo de cómo prácticas musicales de gran impacto y repercusión social han quedado relegadas en la reconstrucción de la memoria cultural e histórica de la España postfranquista. Este artículo documenta la falta de reconocimiento que la rumba suburbana ha recibido para reflexionar después, a través del análisis de la letra de temas representativos de los grupos antes mencionados, sobre el imaginario y la experiencia de la clase obrera.

Palabras clave: rumba suburbana, rumba flamenca, periferia, barrio, desarrollismo, transición, Los Chichos, Estopa.

ABSTRACT: The working-class cultural production has received little recognition in Spain, whose society places artistic practices in the domain of the middle and upper classes. After the $15 \mathrm{M}$ movement in 2011 , cultural criticism has slowly started to retrace and value practices that had been previously considered tacky or marginal due to their blue-collar origins and audience. The suburban rumba of Los Chichos and Estopa is a clear example of how musical practices of extensive social impact have been left out of the historic and cultural reconstruction in postFranco Spain. In this article we document the lack of recognition that suburban rumba has endured in order to analyse, through representative lyrics of the two abovementioned groups, how it represents the working-class values and experiences.

\footnotetext{
${ }^{1}$ A mi tío Carlos, que sabe de rumba y de tantas otras cosas.
} 
Key words: rumba, flamenco, Spanish transition to democracy, Los Chichos, Estopa.

\section{LA RUMBA SUBURBANA EN SU CONTEXTO}

El último cuarto del siglo XX en España supuso un esfuerzo colectivo de transformación social que conllevó la revisión de las normas y valores implantados por la dictadura nacional-católica que dirigió el país entre 1939 y 1975. A pesar del carácter colectivo de este proceso de cambio, el papel desempeñado en él por la clase obrera ha sido frecuentemente obviado (Domènech Sampere, 2003: 91-92), así como ha sido ignorado el valor de su producción cultural. En el terreno musical, en concreto, la transición a la democracia española ha quedado representada por dos manifestaciones disímiles: por un lado, la producción de los cantautores, caracterizada por su tono político y contestatario, y, por otro, un conjunto de prácticas diversas que, en términos generales, celebraba la idea de modernidad inspirándose en la música pop y rock anglosajona e ignorando inicialmente la tradición musical española (Fouce, 2002: 211-225). Esta última manifestación, bautizada como la Movida, ha sido la más celebrada de la escena musical de los años setenta y ochenta, consagrándose como banda sonora del periodo histórico que conocemos como la Transición a la democracia. Jorge Marí señala que, más que un movimiento, la Movida fue un espacio en el que diferentes ideologías y prácticas culturales establecieron un diálogo hasta entonces inexistente en el campo cultural (Marí, 2009: 129). Pese a esta interlocución existente entre los agentes culturales, la reconstrucción histórica y sociocultural del último cuarto del siglo XX no ha sido inclusiva y plural, sino más bien monocorde. Específicamente, en lo que toca al registro musical, esta reconstrucción ha excluido grupos que tuvieron un éxito comparable al de aquellos que han recibido la mayor parte de la atención mediática, que son los que suelen rotular los numerosos estudios que existen sobre esa etapa de la historia reciente de España. Entre estos últimos grupos algunos de los más señalados serían Mecano, Radio Futura o Alaska y los Pegamoides/Dinarama, formaciones que emergen en la escena cultural de Madrid, auspiciada y financiada por el ayuntamiento de esta ciudad a principios de los años ochenta. No es casualidad que estos artistas provinieran en su mayor parte de estratos de la población acomodados, aspecto que marca la visión del mundo que subyace en la forma, interpretación y narrativa de sus temas musicales.

No es hasta bien entrado el siglo XXI cuando surge una crítica revisionista que considera los silencios y exclusiones de la producción académica y cultural española, así como la reconstrucción historiográfica que se ha hecho del último cuarto del siglo XX en el país. En el terreno musical, la exclusión habría afectado a un número de prácticas que no se han avenido con el concepto de modernidad alrededor del cual ha gravitado la narrativa promovida por los discursos institucionalizados. En 2012, y como coro del movimiento del 15M, Guillem Martínez coordinó la edición de una colección de artículos que revisitaban de manera crítica la producción, financiación e institucionalización de lo que este crítico denomina «CT» o Cultura de la Transición, entendida como «el paradigma cultural hegemónico» dominante desde el ultimo cuarto del siglo XX (Martínez, 2016:11). Estudios recientes realizados sobre el campo sociocultural inglés, como el de Owen Jones (2011) o el de Selina Todd (2014), ofrecen un análisis crítico del maltrato y descrédito que sufre la clase obrera y su cultura en otra sociedad profundamente estratificada, la inglesa. En España ha sido sobre todo Vicenç Navarro 
(2006) quien ha dedicado buena parte de su investigación a considerar los efectos del subdesarrollo social que ha sufrido nuestro país, entre los que destaca una acentuada división de clases que opera, sin embargo, de forma velada a fuerza de estar internalizada en los individuos y cristalizada en el sistema.

Anthony Giddens (1984) ha elaborado una teoría social que parte de la base de que, pese a que las sociedades no son sistemas homogéneos, los poderes fácticos obvian las diferencias de tiempo y espacio que se articulan en su seno para establecer una representación totalizadora que les beneficia. En ese sentido, la prevalente CT, presuntamente democratizadora e igualitaria, ha evitado cuestionar el clasismo institucional de una sociedad que no ha dedicado el suficiente esfuerzo a desmontar privilegios sociales patrimoniales. El campo cultural e intelectual español sigue dominado por discursos que están lejos de legitimar prácticas culturales que no sean las que considera propias, es decir, las que están alineadas con sus intereses materiales o simbólicos.

El presente artículo es una reflexión sobre una zona de la producción musical que ha sido considerada marginal a pesar de su éxito de audiencia y ventas: la rumba flamenca de los suburbios urbanos, también conocida como rumba gitana, rumba vallecana o rumba quinqui y que, en este trabajo, llamaremos rumba suburbana ${ }^{2}$. Sería esta una de las expresiones musicales que aparece durante los últimos años del franquismo y los primeros de la transición a la democracia para reproducirse más tarde en grupos que hacen su aparición a finales de siglo XX. Inicialmente, esta producción verbaliza por primera vez la experiencia de la clase obrera y, por ello, tiene su origen en la zona periférica de las grandes ciudades españolas, zona construida precariamente al calor del desarrollismo industrial de los años sesenta y setenta, social y espacialmente segregada, que durante la crisis económica de los años setenta y ochenta sufre enormemente las dramáticas consecuencias de una alta tasa de desempleo y del consumo de drogas. La mayor parte de los habitantes de estos enclaves urbanos había llegado desde las zonas rurales, especialmente desde el Sur de España, y, entre otros muchos desafíos, se vio obligada a adaptar sus formas de vida tradicionales a nuevos espacios que frecuentemente carecían de infraestructura o de servicios básicos. El concepto de clase obrera es fluido y heterogéneo y, a los efectos de nuestro estudio, alude a los trabajadores asalariados o autónomos que dependen de su trabajo, manual o de servicio, para subsistir. Los barrios en los que se asienta la clase obrera son también espacios heterogéneos que en ocasiones contienen zonas depauperadas con mayores índices de desempleo o delincuencia. ${ }^{3}$ Pese a esta heterogeneidad, en la España tardo-franquista esta clase social comparte una experiencia del mundo similar en virtud de su cultura tradicional — de marcado carácter rural - y de su mermada capacidad adquisitiva, que se traduce en las particularidades de los espacios vividos, así como en su cultura material, horizonte de expectativas y relaciones sociales. El crecimiento exponencial de este grupo social en ese momento histórico origina el surgimiento de una conciencia sociopolítica que está en la base de las

\footnotetext{
${ }^{2}$ Creemos que este término es más inclusivo que los usados hasta ahora. La rumba flamenca es el género original o de base, pero no toda rumba flamenca es rumba suburbana. Por su parte, el término rumba gitana, quizá el menos utilizado, parece ser utilizado como sinónimo de rumba flamenca. Finalmente, rumba vallecana delimitaría el género a su producción en el Madrid de los años setenta y rumba quinqui alude también a la misma época, además de tener una connotación negativa que, como se verá más adelante en este artículo, está vinculada al uso que el denominado 'cine quinqui' hizo de la rumba suburbana.

${ }^{3} \mathrm{~J}$. Vilagrasa señala que la carencia de vivienda urbana durante las primeras décadas del franquismo produjo asentamientos de autoconstrucción y barraquismo. No obstante, el cambio de legislación en materia de vivienda de 1958, que abrió la puerta al sector privado, y el Plan Nacional de Vivienda (1961-1976) dieron como resultado la creación de numerosos barrios de nueva planta que fueron donde mayoritariamente se asentó la clase obrera (1997: 16-17).
} 
numerosas movilizaciones obreras que tuvieron lugar a mediados de los años setenta (Domènech Sampere 2011: 187-190). Es esta conciencia de pertenencia, expresada en reivindicaciones y acciones colectivas en pro del interés colectivo, la que legitima la existencia del grupo. Todos estos elementos, experiencia cultural, entorno material y conciencia social, operan en la génesis de la rumba suburbana.

La rumba suburbana es heredera de la rumba flamenca, que tiene su origen en ritmos cubanos que fueron aflamencados a su llegada a España en la segunda mitad del siglo XIX, haciéndose popular gracias a los espectáculos de variedades que cobraron auge a principios del siglo XX (Pérez Custodio, 2005: 96). Entra dentro de los cantes de ida y vuelta del flamenco, es decir, de aquellos géneros que tienen influencia u origen en formas musicales generadas en la América hispana (Núñez, 1998: 11, citado en Pérez Custodio 2005: 97). Su tono ligero la emparenta con la copla andaluza o la canción española y, al igual que estos géneros, fue instrumentalizada por el populismo franquista para promover la imagen de una España presuntamente auténtica: sureña (de un gitanismo idealizado y estético), preindustrial, tradicional y católica. El franquismo no fue original en ese sentido, pues la representación estereotipada del casticismo y del flamenquismo había sido habitual entre las élites del país desde hacía siglos. Este orientalismo ibérico contribuyó a reforzar la discriminación de los gitanos, que quedaron cosificados en su representación social. La rumba que emerge en la periferia urbana aprovecha esta conexión con formas musicales legitimadas y reproducidas institucionalmente para darle una vuelta de tuerca al género y cuestionar en sus letras la desigualdad social que afecta a un sector de la población, recuperando así el tono de denuncia social que ha caracterizado al flamenco tradicional (Ortiz Nuevo, 1985).

Por otro lado, la rumba suburbana tiene una estrecha conexión con la rumba catalana, variante de la rumba flamenca forjada en los barrios gitanos barceloneses a mediados del siglo XX y que se caracteriza por su tono festivo, así como por su particular forma de realizar la percusión y el rasgueo de la guitarra. La rumba suburbana, no obstante, está dominada por un pathos muy diferente, marcado por la expresión del desencanto y el lamento ante la adversidad. Además, la incorporación de aspectos propios de la música pop y rock le confiere una cierta modernidad que ni la rumba flamenca ni la catalana poseían. Estos elementos modernizantes respondieron a las estrategias mercadotécnicas de la emergente industria discográfica española, que vio en la rumba suburbana un género idóneo para llegar a un amplio sector de la población. ${ }^{4}$

Así, grupos como Los Chichos, Los Chunguitos o, más tarde, Los Calis ${ }^{5}$ expresaban y producían a través de este género la experiencia e identidad, tanto subjetiva como colectiva, de buena parte de la clase obrera que habitaba la periferia urbana española. La mayoría de estos músicos provenían de la comunidad gitana y, como tales, eran portadores de una rica tradición musical flamenca, compartida con payos de origen andaluz y extremeño. Con un bagaje cultural esencialmente rural y tradicional, los inmigrantes del Sur encuentran en la rumba el ritmo adecuado para verbalizar y hacer comprensible su precaria experiencia de la ciudad y de sus formas de interacción social. La producción que la industria discográfica hizo de este género dio una gran popularidad

\footnotetext{
${ }^{4}$ Esta hibridación musical entre flamenco y pop-rock tiene su expresión más elaborada en el denominado "sonido Caño roto" que practicaron grupos como Los Chorbos o Las Grecas, ambos producidos por José Luis de Carlos. A pesar de ser valorados por la crítica, y citados repetidamente en los estudios musicales, no alcanzaron el sostenido éxito comercial de Los Chichos o Los Chunguitos.

${ }^{5}$ Los nombres de estos grupos sugieren ya la extracción social de sus miembros, pues se forman con el artículo y el apodo, modo característico del habla popular para designar a personas del entorno familiar. Frente a estos, los nombres de los grupos de la Movida carecen de artículo y aluden a objetos y medios tecnológicos o industriales, como radio, mecano, pegamoide o dinarama.
} 
a ciertos grupos y temas, contribuyendo a que la rumba se gestara y se consumiera en el barrio, en torno a una guitarra y una litrona - botella de litro de cerveza. En este sentido, son interesantes las apreciaciones que Gerhard Steingress hace a propósito de la rumba urbana de los años setenta:

Más que flamenco, estos sonidos de los 70 podrían ser clasificados como la manifestación de una nueva y más amplia estética musical del flamenco ante los nuevos y dramáticos retos de la vida de los sectores sociales marginados y desprotegidos de las grandes urbes como Madrid o Barcelona, con su miseria, la fascinación por las drogas, el estilo de la nueva bohemia y la sensación de "gran libertad" que ofrecía la España postfranquista. La música en general y el flamenco en particular se consideraron como expresiones manifiestas de un "nuevo sentir" (...)

(Steingress, 2004:s/p)

Peter Manuel arguye igualmente el carácter socioeconómico de formas musicales que emergen en el marco de la diáspora andaluza, motivada por la pobreza ancestral y la falta de oportunidades en su tierra. Manuel habla de un continuum musical entre estas nuevas formas urbanas y el flamenco o la tradición musical del Sur español (Manuel, 1989: 47-48). Ese «nuevo sentir» del que habla Steingress, expresado en la rumba, era el sentir del barrio obrero periférico, compartido por los habitantes de las zonas rurales del Sur peninsular, igualmente afectados por una brutal desigualdad social. El éxito de ventas de Los Chichos fue extraordinario; formado en Vallecas en 1973 por Juan Antonio Jiménez Muñoz, conocido como el Jero o Jeros, y los hermanos Emilio y Julio González, el grupo se mantuvo en activo durante casi cuatro décadas. No obstante, a partir de 1990, cuando Jeros, compositor de sus temas más celebrados, decidió proseguir su carrera en solitario, la formación se vio afectada permanentemente. Con todo, en 1999 el diario El País calculaba el volumen de ventas del grupo en más de quince millones de discos (Mora, 1999:s/p); por su parte, López Castellano habla de 22 millones de discos y de 20 millones de casetes (2018: 11), lo cual es muy importante si consideramos que el acceso que los habitantes de la zona suburbial tenían a productos musicales era a través de los estantes de las gasolineras, que vendían exclusivamente cintas de radiocasete. Sin embargo, en la reconstrucción de la historia cultural de la España del siglo XX, la narrativa hegemónica ha caracterizado a Los Chichos y a otros grupos similares como marginales, relegándolos a un lugar menor.

Una de las razones que contribuye a que la rumba suburbana haya quedado asociada en el imaginario colectivo a la marginalidad es que fue utilizada por el denominado cine quinqui como banda sonora. Significativamente, este tipo de cine tampoco ha recibido, pese a su éxito de audiencia, atención crítica hasta hace pocos años (Whittaker, 2012: 100) ${ }^{6}$. Caracterizado por su tono social -no exento de paternalismo-y por su efectismo (Imbert, 2015: 64), el cine quinqui generalmente presentaba como héroes a delincuentes, históricos o ficticios, de los suburbios urbanos. En varias de las películas realizadas por José Antonio de la Loma, uno de los directores más representativos de este tipo de cine, la banda sonora estuvo a cargo de Los Chichos y de Los Chunguitos, por lo que sus temas han quedado permanentemente asociados a las escenas de delincuencia que acompañaban. La música de las películas quinquis es uno de los elementos fundamentales de estas porque precisamente es una de las expresiones culturales con las que los

\footnotetext{
${ }^{6}$ La exposición (y catálogo correspondiente) Quinquis de los 80 ofreció un interesante compendio del contexto social en que se recrea la figura del quinqui (Cuesta y Cuesta 2009).
} 
habitantes de estos nuevos espacios (que no son ni urbanos ni rurales) dan sentido a su medio y a su experiencia (Whittaker, 2012: 107). ${ }^{7}$

En términos étnicos, es interesante señalar aquí que la palabra "quinqui" aludía originalmente a los individuos pertenecientes a un grupo minoritario y nómada que solía recorrer las zonas rurales de Castilla y Extremadura. Los quinquis, también conocidos como mercheros, reparaban o comerciaban con quincalla -utensilios metálicos de carácter doméstico-, es decir, eran quincalleros o quinquilleros, y de ahí su denominación. Este oficio ha sido también tradicionalmente desempeñado por grupos de gitanos (tanto españoles como de otros lugares, como los kalderash ${ }^{8}$ de la Europa del Este). Aunque étnicamente quinquis y gitanos son diferentes, ambos grupos han coincidido y han sido asociados debido a que comparten formas de vida y de relación social ligadas a la itinerancia. En la sociedad española de mediados del siglo XX el término «quinqui» era utilizado generalmente de manera despectiva para designar a los mercheros, pero también para insultar a aquellos que, sin ser gitanos, lo parecían, es decir, era un insulto basado en los prejuicios raciales dominantes en la sociedad española. De ahí que se le aplicara a los delincuentes del barrio obrero que no eran ni quinquis/mercheros ni gitanos étnicamente. En ese mismo sentido también se utiliza todavía el término «calorro», que proviene de «calorró», palabra del caló con la que los gitanos se denominan a sí mismos. Puesto que la discriminación racial opera también a nivel socioeconómico, los prejuicios sobre los gitanos en España han afectado tanto a su fenotipo y a su cultura como a sus modos de vida, oficios y, en definitiva, a su posición social. De ahí que también hayan sido racializados y discriminados aquellos payos que han ocupado una posición social contigua o similar. Si desde los valores hegemónicos se percibe a los habitantes payos del barrio obrero y a los gitanos con cierta homogeneidad es porque, efectivamente, comparten un espacio sociocultural común que determina buena parte de sus prácticas culturales, entre las que se encuentra el flamenco, un género híbrido y esencialmente andaluz. Con todo, es de justicia señalar que este se reproduce y evoluciona de manera especial en el seno de la comunidad gitana, a pesar de que esta esté poco representada a nivel institucional, en particular en lo que toca a la administración de este bien cultural (Lenore, 2016: 118-119).

Volviendo al cine quinqui y a la etiqueta de marginalidad que la rumba suburbial recibió por su conexión con este, conviene explicitar que la vida de la mayoría de quienes se asientan o crecen en la periferia urbana durante los años sesenta y setenta poco tiene que ver con la de los delincuentes representados en los filmes de la época. En cierta medida el cine quinqui sirvió para reforzar la marginación de la clase obrera que habita la periferia urbana (Castelló Segarra, 2018). Ciertamente, el habitante del barrio pudo reconocer como familiares las circunstancias y los espacios que marcaron la trágica vida de los delincuentes representados en las películas, sintiendo una relativa identificación. No obstante, ni la precariedad laboral, ni el acecho de las drogas o las difíciles condiciones de vida llevaron a la mayoría de los jóvenes de la periferia a delinquir. La figura cinematográfica del quinqui recoge a un sujeto marginal incluso dentro del propio barrio obrero, sin embargo, su representación (superficial las más de las veces) cinematográfica supone una falsa sinécdoque entre este y el espacio social que habita. Esta extensión de la condición marginal a todos los habitantes de la periferia oculta que estos tuvieron una contribución sustancial al denominado cambio, contribuyendo al desarrollo industrial con duras jornadas laborales y alimentando el crecimiento económico. Si bien algunos de los

\footnotetext{
${ }^{7}$ Para más información sobre el cine quinqui y su relación con la rumba flamenca vide Whittaker 2020.

${ }^{8}$ Esta palabra significa «calderero» y designaba a los grupos que se dedicaban a reparar las calderas de lata y cobre, así como otros utensilios de uso doméstico.
} 
jóvenes habitantes de los nuevos barrios obreros se quedaron en ellos cuando se emanciparon y adquirieron su vivienda «a letras» ${ }^{9}$, muchos se mudaron más allá del barrio, a barrios de nueva planta situados en pequeñas localidades que dieron en crecer y se convertirían en ciudades-dormitorio. Sus hijos, nacidos a partir de finales de los años sesenta, crecerán también con la rumba que sonaba en ciertas emisoras radiales, en sus reuniones familiares, fiestas del barrio o en el coche, y volverán con ellos al Sur en las vacaciones, percibiendo de soslayo la miseria que llevó a su familia a buscar una vida mejor en ciudades como Madrid o Barcelona. Gracias al enorme esfuerzo desarrollado por sus abuelos y sus padres, será esta la primera generación obrera que consiga llegar a la universidad, rompiendo parcialmente una barrera social que había demarcado la sociedad española durante siglos. El cine quinqui, concebido y realizado por personas que no pertenecían al entorno obrero, presenta al delincuente de barrio como víctima social y como héroe rebelde que hace frente con desparpajo a lastres de la época franquista, como la desigualdad, la segregación social, la corrupción y la violencia de las fuerzas del orden. No obstante, este tipo de cine se olvida de ampliar su enfoque y dirigir la cámara hacia la mayoría de jóvenes que crece en los barrios y lidia con los escollos de un entorno hostil sin caer en la criminalidad. Al centrarse en los aspectos más marginales del barrio y utilizar la rumba suburbana como coro, el cine quinqui ha contribuido a reforzar la etiqueta de marginalidad que ha quedado asociada a este género. Sin embargo, este tipo de música no era producida y consumida por delincuentes, sino por los habitantes del barrio obrero que, como acabamos de explicar, realizan una gran contribución social que ha quedado silenciada en la reconstrucción histórica.

Los estudios etnomusicológicos sobre esa época son aún escasos y solo ocasionalmente señalan la discriminación que opera en el campo cultural español. Así, por ejemplo, en el año 2013, la editorial Routledge publicaba el volumen Made in Spain. Studies in Popular Music como parte de una amplia colección, Global Popular Music Series, de distribución internacional y destinada a especialistas en la materia. La colección se precia de ofrecer obras editadas y escritas por expertos que viven y trabajan en los países o áreas estudiados (ii). Made in Spain está efectivamente realizado por destacados especialistas y se encarga de una zona de la cultura poco estudiada hasta ahora, cuestionando en ciertos pasajes el discurso institucional que produce y reproduce la cultura mainstream como la única cultura nacional (Fouce y del Val, 2013: 125-127) ${ }^{10}$. Sin embargo, la edición también incurre en silencios y olvidos. Los editores, Silvia Martínez y Héctor Fouce, señalan en la introducción de la obra que los inmigrantes que llegaron desde las zonas rurales a las grandes ciudades durante los años 60 y 70 se asentaron en barriadas subdesarrolladas que fueron focos de protesta política. A continuación, añaden que los migrantes llegados desde Andalucía a Madrid y Barcelona recrearon a su manera estilos de origen flamenco, como la rumba (Martínez y Fouce, 2013: 8-9). En principio, el lector esperaría algunas referencias específicas a la relación entre los suburbios urbanos y la rumba, tal y como ha sido anunciado en la introducción. Sin embargo, el primer capítulo, firmado por Enric Folch (2013) y dedicado a la rumba flamenca $^{11}$, no hace ninguna alusión a ello. Folch intenta realizar una difícil síntesis de la genealogía del flamenco y de la rumba, que queda en ocasiones reducida a un listado de nombres y conexiones. Llama la atención que cuando habla del rock gitano suburbano madrileño, el autor menciona a Las Grecas y a Los Chorbos, grupos efímeros y cuyos

\footnotetext{
${ }^{9}$ Expresión que hacía referencia a las letras de cambio, la práctica de pago habitual en aquella época.

${ }^{10}$ Fouce y del Val hablan del olvido que han sufrido grupos de rock duro que emergieron en el contexto de los barrios obreros, como Leño o Nu.

${ }^{11}$ El capítulo se titula «At the Crossroads of Flamenco, New Flamenco and Spanish Pop. The Case of Rumba» [Entre el flamenco, el nuevo flamenco y el pop español. El caso de la rumba].
} 
temas tuvieron mucho menos impacto social que los de Los Chichos. La banda sonora de los suburbios obreros de Madrid durante los años setenta y ochenta está compuesta por una mezcla de sonidos ecléctica y transversal, que pasa por diversos estilos musicales y diferentes grupos, entre los que estarían Tequila, Loquillo, Radio Futura, Leño y otros, pero si hablamos de rumba flamenca Los Chichos son una mención obligada. El hecho de que Folch no los mencione inicialmente resulta llamativo, puesto que se alude a grupos que tuvieron un éxito menor, pero aún resulta más sorprendente que, unas páginas más adelante, se mencione a Los Chichos de soslayo: si bien se indica que, efectivamente, fueron un grupo de rumba de gran éxito en los años 70 y 80 , se los menciona para explicar el éxito de la cantante Niña Pastori a finales del siglo XX que, según el crítico, se debía en parte a la aportación de su marido, Chaboli, hijo de Jeros.

En otra compilación aparecida en el mismo año, Rock around Spain. Historia, industria, escenas y medios de comunicación, se incluye un artículo dedicado al rock andaluz que se centra en explicar el surgimiento y la entrada en la escena musical de grupos como Triana, compuestos por «músicos de rock con pasión por el flamenco y gustos arabizantes»(Clemente, 2013: 140), señalando brevemente que existen otras formas de rock aflamencado, como el flamenco rock, el rock gitano y el gypsy rock (ibid. 139). En nota a pie de página, los editores explican que el flamenco rock estaría compuesto por grupos como Kiko Veneno o Navajita Plateá, entre otros, el rock gitano por grupos como Pata Negra, y el gypsy rock por Las Grecas, Los Chorbos, Manzanita, Los Chunguitos o Los Chichos, señalando que este último tipo de rock influye en grupos populares como Estopa (Mora y Viñuela, 2013: 139). Así pues, en un volumen dedicado al rock español de las últimas décadas solo figura una nota a pie de página para hablar de Los Chichos y de Estopa, dos de los grupos de mayor éxito de ventas de las últimas décadas. Efectivamente, se podría cuestionar la pertenencia de la rumba suburbana al «rock» - sobre todo en el caso de Los Chichos, no tanto en el de Estopa-, pero esto afectaría también a otras prácticas musicales que, sin embargo, sí figuran en el volumen. Creemos que esta mención, breve y secundaria a pie de página, es significativa del maltrato que la rumba suburbana ha sufrido a manos de buena parte de la crítica.

En este contexto, no resulta sorprendente que, cuando en el año 2014 Fernán del Val et al. propongan un canon del pop-rock español, ni Los Chichos ni Estopa estén incluidos, ya que no figuraban, a excepción de una mención a Estopa, en las fuentes utilizadas para la conformación del canon: los rankings establecidos por cuatro revistas musicales especializadas ${ }^{12}$. En uno de los escasos artículos académicos dedicados a la rumba suburbana, López Castellano señala acertadamente que, como género verdaderamente subalterno, la rumba ha quedado fuera del canon y del discurso cultural hegemónico (2018: 11). Por su parte, Lenore señala que la discriminación que opera en las instituciones culturales españolas desde la Transición afecta a los géneros que incorporan crítica social, como la rumba o el rock duro, o a aquellos cuya estética es considerada de mal gusto, pues no se aviene con la pátina de modernidad y progresía de la narrativa cultural hegemónica. Así, por ejemplo, el grupo de rumba Camela, con un gran éxito de público, ha sido ignorado o subestimado sin ambages por todos los medios culturales (2016:116-117).

La rumba suburbana interpretada por grupos como Los Chichos ${ }^{13}$, Los Chunguitos, Los Calis o, ya entrando en el siglo XXI, por Estopa, entre otros grupos, posee una estética (formal y de contenido) que no ha sido ni es considerada Cultura, con énfasis

\footnotetext{
${ }^{12}$ En estas listas sí entraban, sin embargo, otros intérpretes de rock flamenco, como Kiko Veneno, Triana o Pata Negra, cuya producción no ha sido asociada con lo barrial.

13 Para los efectos de este estudio considero esta formación entre 1973 y 1990, cuando Juan Antonio Jiménez Muñoz forma parte de ella y cuando produce sus temas más representativos.
} 
en la mayúscula. Por sus características formales y su éxito entre los grupos más humildes de la sociedad, se considera una producción de baja calidad y no ha sido tenida en cuenta en la narrativa cultural de la España de las últimas décadas, basada en la idea de modernidad y europeísmo. No solo es contradictorio, sino también perverso, que se ignore o califique de marginal la producción cultural de quienes conforman un extenso grupo social que ha cargado, literalmente, con el peso del esfuerzo económico y social realizado en la historia más reciente del país (Domènech Sampere 2011: 179-180).

\section{LA ESTÉTICA SUBALTERNA DE LA RUMBA EN LOS CHICHOS Y ESTOPA}

Los emigrantes que llegaron a las ciudades en vías de industrialización en los años cincuenta y sesenta procedían de medios rurales cuya pobreza secular se había visto agravada por la guerra civil y sus consecuencias. A pesar de que eran en gran medida analfabetos (Viñao, 2009: 9-13), contaban con una rica tradición oral trasmitida a través de canciones, cuentos, leyendas, rituales y celebraciones que daban sentido a su posicionamiento en el tiempo y el espacio, y con ello a su identidad social. El proceso de migración hacia las grandes ciudades supuso una ruptura con sus formas de vida y sus formas de entender el mundo, obligándolos a adaptar sus saberes al nuevo contexto industrial y pseudourbano -0 de un urbanismo liminal. La rumba suburbana es una práctica de agencia en tanto intenta dar sentido a la nueva experiencia de un sujeto dislocado que ha perdido sus puntos de referencia. Al igual que el flamenco tradicional, este género parte de un locus enunciativo periférico que la cultura hegemónica etiquetará como marginal. Vinculada a la tradición musical del Sur español, la rumba incorpora también elementos del pop y del rock con el objetivo de adaptarse, sobre todo en términos de mercado, a la pretendida modernidad de las urbes en vías de industrialización. A través de su ritmo rápido, su intensidad emocional y su visión desilusionada del presente, la rumba es un intento de dar sentido al descentramiento de un sujeto cuya experiencia no responde al sistema de relaciones de la modernidad urbana, pero tampoco ya al de la tradición rural. En su obra, Giddens enfatiza la idea del individuo como sujeto cuya agencia y saber están condicionados por el sistema de relaciones espacio-temporales en que se sitúa. El habitante del barrio tiene un capital cultural que resulta inadecuado para la modernidad urbana. Paradójicamente, su intento de adaptar ese capital al nuevo medio resulta fallido en tanto que la cultura hegemónica va a designar la rumba como una producción marginal.

En su extenso estudio sobre los procesos de la memoria, Maurice Halbwachs ([1925] 1994, [1950] 1997) afirma que el individuo solo puede estructurar sus recuerdos, y por ende conferir sentido a su existencia, en una base social organizada en torno al lenguaje y a las coordenadas de tiempo y espacio. El espacio está definido en función de las características geográficas, la organización urbana y la arquitectura, pero también, y sobre todo, se define como producto y proceso social, pues es un espacio de representación y un espacio vivido. (Lefebvre, 2000: 35-50) El espacio está hecho por el habla, origen y herencia cultural de quienes lo habitan, por sus ocupaciones laborales, sus modelos de familia y las relaciones que se desarrollan en su seno. De ahí que la rumba, en tanto incorpora todos estos elementos, resulte tan significativa para los obreros, pues no solo parte de una experiencia, sino que también la produce, es decir, expresa y da forma al mismo tiempo a una forma de estar en el mundo, integrando lo individual y lo social (Frith, 1996:187). La música de un grupo social, delimitado por el espacio y el tiempo que habita, es fundamental para entender no solo su identidad étnica, sino también la propia subjetividad de los individuos (Ibid. 185-6). 
La Transición, como proyecto político y como construcción cultural e histórica, se ha elaborado con un lenguaje y unas coordenadas espacio-temporales poco representativas de la heterogeneidad social española. Los bloques de pisos diseminados en descampados, las ferias ambulantes que animaban las fiestas del barrio, la frustración del desempleo, los oficios manuales y el acento rural son un referente necesario de la historia española de la segunda mitad del siglo XX. Sin embargo, estos elementos y las formas de vida que los acompañaban no han sido integrados, salvo contadas excepciones, en el imaginario oficial de ese momento, elaborado sobre una modernidad que era fragmentaria y burguesa. Sí forman parte esos elementos de la narrativa de las composiciones de Los Chichos ${ }^{14}$ y Estopa. Estos dos grupos son de los más representativos de la música del barrio suburbano y así lo demuestra el enorme éxito que ambos han alcanzado. Su representatividad se basa en que utilizan formas musicales que son significativas para la clase obrera, pues entroncan con su acervo cultural rural, al tiempo que se adaptan a su nuevo medio urbano. Además, se expresan con el habla propia de los barrios suburbanos y en sus temas se legitiman las experiencias de quienes los habitan. Las canciones de Los Chichos y de Estopa nos ubican en el barrio como espacio vivido tanto por su forma como por su contenido.

Tal y como hemos señalado anteriormente, la rumba flamenca, como forma musical, es desde sus orígenes un género eminentemente popular y popularizado, hasta tal punto que los puristas lo consideran un género menor del flamenco. Por otra parte, la entonación y el acento de la mayor parte de los intérpretes de la rumba suburbana deja ver un claro origen andaluz o extremeño, y está marcado por el deje propio del habla del barrio periférico. Su lenguaje es coloquial y hacen uso frecuente de términos procedentes del caló o de la jerga juvenil. Sus contenidos, por su parte, son un archivo elocuente de la experiencia del mundo de los habitantes del extrarradio en la España del cambio.

En 1985, José Antonio de la Loma dirigió una de las películas más distintivas del cine quinqui, Yo, El Vaquilla, encargándole la banda sonora completa a Los Chichos ${ }^{15}$. No es de ninguna manera casual que estos le dedicaran un tema al Campo de la Bota de Barcelona, el barrio en el que creció el protagonista de la cinta. En esta composición, Jeros le da voz a El Vaquilla para cifrar hábilmente una aparente paradoja: el apego que sienten por el barrio sus habitantes, a pesar de ser conscientes de su condición inhóspita. Los individuos solo pueden conferir sentido a su experiencia en el marco del espacio y del tiempo que viven, de ahí que el barrio sea un lugar hostil, marcado por la precariedad económica y la necesidad de supervivencia, pero querido al mismo tiempo.

Tú tienes la llave del corazón mío,

Campo de la Bota donde yo he vivío ${ }^{16}$.

Nadie quiere saber nada,

aquí tan solo se compra y se vende.

Cada persona es un mundo

y cada uno vive como puede.

Por eso nadie pregunta

que dónde vas o de dónde vienes.

Aquí mueren los chivatos,

\footnotetext{
14 Para los efectos de este estudio considero esta formación entre 1973 y 1990, cuando Juan Antonio Jiménez Muñoz forma parte de ella y cuando produce sus temas más representativos.

${ }^{15}$ Esta cinta fue un biopic sobre Juan José Moreno Cuenca (1961-2003), delincuente mítico que ha quedado representado en temas musicales y obras literarias como una víctima del sistema. En el tema central de la película, «El Vaquilla», Los Chichos le caracterizan como un «alegre bandolero [...], de buenos sentimientos $[\ldots]$ porque lo que ganas repartes el dinero».

${ }^{16}$ En la transcripción de las canciones se utiliza ocasionalmente el dialecto visual.
} 
a los chivatos nadie los quiere. [...]

Tienen ginda los maderos y no camelan entrar ni de día. ${ }^{17}$ Piensan que esto es un infierno y no es tan fiero el león como lo pintan. Aquí vive el bueno y [el] malo, tenemos penas más que alegrías, callamos si hay que callarse, nos defendemos y damos la vida.

(Los Chichos, 1985)

El habitante del barrio tiene un código o saber que le permite sobrevivir en un espacio en el que gobiernan reglas de conducta (el silencio, la solidaridad) que garantizan un cierto orden. La policía encarna la autoridad y el poder, pero también lo ajeno, lo que no pertenece al barrio y no puede, por lo tanto, comprenderlo. Al utilizar el verbo «entrar», Los Chichos representan la realidad de los barrios suburbanos de la España tardo-franquista: espacios segregados que no tienen continuidad con el centro urbano. «Entrar» en el barrio no es solo una idea física, sino también cognoscitiva, pues este funciona con códigos propios.

Por su parte, los hermanos David y José Manuel Muñoz, que formaron Estopa en 1999, crecieron en uno de los barrios obreros más mentados de la España suburbana, Cornellá de Llobregat, en el cinturón industrial barcelonés. Este barrio es el lugar de enunciación de sus composiciones y el espacio en el que se contextualizan las historias que cuentan. De manera muy similar a lo que hicieron Los Chichos en «Campo de la Bota», en «El Blade» (Destrangis, 2001) Estopa presenta el barrio como un espacio hostil y familiar al mismo tiempo, regido por leyes propias:

Que en Cornellá dónde las dan las toman.

Siempre sabes dónde las dan y tú las tomas, pero eso sí, aquí en Cornellá.

$[\ldots]$

No pudiste elegir, entrar o salir.

Pudiste sobrevivir, vivir, vivir, pero en el parque me llaman y en Cornellá quien no llora no mama.

$[\ldots]$

Y si los dioses supieran

que un tío de barrio les supera.

La eterna espera

porque en mi barrio siempre es primavera.

(Estopa, 2001)

El barrio de «El Blade» es un espacio no elegido, limitado y marcado por la necesidad, pero aceptado y reivindicado por los sujetos que son capaces de sobrevivir en él. Significativamente, en una reciente entrevista, los miembros de Estopa insistían en su identidad obrera y barrial: «[...] nos llaman garrulos, calorros, gente de barrio bajo... Lo dicen despectivamente sin saber que esos supuestos insultos a mí me enorgullecen. Aguantamos mucho clasismo por ser de clase obrera. Antes y ahora». (Díaz-Guerra, 2019)

${ }^{17}$ El sustantivo «ginda» [miedo] y el verbo «camelar» [querer] son lengua caló, mientras que el término «maderos» [policías] pertenece al español jergal de ese momento histórico. 
El barrio no necesita estar explícitamente mencionado en los temas de Los Chichos y de Estopa porque figura siempre como el lugar de enunciación, expresando la visión del mundo de sus habitantes, cifrada en un pathos que está claramente ilustrado por la canción de Los Chichos que da título a esta ponencia: «Son ilusiones» (Son ilusiones, 1977).

Hay veces que me pregunto, pero no sé contestarme, lo que hacemos en la vida luego de nada nos vale. Todo es una mentira, todo se lo lleva el aire. Hay veces que me pregunto, pero no sé contestarme. [...]

(Los Chichos, 1977)

El tema expresa la estética del desencanto que domina la rumba suburbana y representa el sentir de los habitantes del barrio de extrarradio, sometidos a una vida de esfuerzos a la que no consiguen dar un sentido. Al musicalizar la frustración que produce la falta de oportunidades, la precariedad laboral o el desempleo, el trabajo físico, el refugio en la drogadicción, Los Chichos y Estopa legitiman esas experiencias. No es de extrañar que este tema fuera versionado por Estopa en el año 2000, es decir, más de veinte años después, ofreciendo una interpretación más roquera que volvió a ponerlo de moda, convirtiéndolo en un clásico de la música popular española del siglo XX. Ya en su primer disco, los de Cornellá habían hecho un elocuente homenaje a Jeros con el tema «El del medio de Los Chichos», que forma parte hoy de la memoria cultural de la clase obrera española. Es significativo que, para denominar al cantante, no se utilice su nombre, poco conocido entre el público, sino que se aluda a la posición habitual que ocupaba en las fotografías y en el escenario, imagen que los seguidores pueden evocar fácilmente. En esa composición Estopa declaraba la influencia que Jeros y el grupo de Vallecas habían tenido sobre su práctica musical.

El del medio de Los Chichos

se me ha aparecío en sueños, se me ha aparecío y me ha dicho: «de tu rumba soy el dueño». El del medio de Los Chichos me ha dicho que en la otra vida se le han olvidado las penas, se acuerda de la alegría, pero me ha dicho que está muy sólo, ya no tiene compañía.

[...]

Me ha dicho que en otra vida Yo era un perro callejero.

[...]

El del medio de Los Chichos me ha pedido dos favores: que sea su mensajero y una canción de colores. Me ha dicho que abra las puertas, que abra también los balcones y que cante esta rumbita $\mathrm{p}^{\prime}$ alegrar los corazones. $[\ldots]$ 
El tema no solo rinde homenaje a Jeros, también establece una poética de la rumba suburbana — «una canción de colores (...) p'alegrar los corazones»— desde Los Chichos hasta Estopa. El yo lírico se reconoce, por mediación de Jeros, como «perro callejero», expresión despectiva utilizada para designar a los jóvenes de barrio que crecen en la calle sin supervisión constante. Además de apropiarse y resignificar una expresión normalmente utilizada como insulto, Estopa alude también a otro hito del cine quinqui, Perros Callejeros (1977), algunos de cuyos temas musicales fueron compuestos por Los Chunguitos. El tema de Estopa señalaba la contribución a la música española de Jeros, quien será conocido a partir de ese momento como «el del medio de Los Chichos».

La visión y experiencia del mundo expresada en los temas del grupo de Vallecas es revisitada frecuentemente por Estopa (Pàmies, 2001:s/p). Así, por ejemplo, si la adicción a la heroína, una epidemia que afectó a los barrios periféricos durante los años ochenta, fue denunciada en varios de los temas más representativos de Los Chichos «¿Dónde vas?» (Ni tú ni yo, 1982) o «En vano piden ayuda» (Ojos negros, 1988)—, Estopa también dedica algunas de sus composiciones más celebradas a los efectos de la cocaína a finales de los años noventa en «Exiliado en el lavabo» (Estopa, 1999) o en «El yonki» (Destrangis, 2001). No obstante, en Los Chichos hay una aproximación a temas relacionados con fenómenos sociales marginales, como la delincuencia o la prostitución, que no se da en Estopa de la misma forma. En «La historia de Juan Castillo» (Ni más ni menos, 1974), Los Chichos dan voz a un preso que se lamenta del futuro que les espera a sus hijos ahora que él está en la cárcel por haber matado a quien delató sus planes de robo. Este fue uno de los temas de mayor impacto del grupo y ha sido versionado repetidamente, incluso a pesar de que en las estrofas centrales se hace uso de varios términos procedentes del caló, lo que dificulta la comprensión para la audiencia paya. Por su parte, la prostitución aparece mencionada en varios de sus temas, frecuentemente en relación con los sentimientos de amor o desamor del yo lírico, como es el caso de «Amor de compra y venta» (Amor de compra y venta, 1980). En Estopa, sin embargo, hay una vivencia del medio más normativa, pues no en vano ha trascurrido un cuarto de siglo en el que España se ha transformado sustancialmente. Con todo, sus temas están marcados por el desencanto, incluso cuando versan sobre los sentimientos o el deseo sexual, y están escritos con el lenguaje del barrio y desde su imaginario. Así lo expresa el tema «Fábricas de sueños»:
Fábricas de sueños,
vertederos de historias,
humos de recuerdo,
olvidos de memoria.
$[\ldots]$
Y en la plaza del mercado,
ya no se cuentan cuentos,
han echado a los viejos.

(Estopa, 2005)

En ocasiones, Estopa retrata los aspectos conflictivos del barrio, como sucede en «Partiendo la pana» (Destrangis, 2001), pero sus temas no abundan en actividades delictivas ni marginales y, si lo hacen, como en «Cacho a cacho», es una marginalidad estética que les sirve para homenajear al cine quinqui ${ }^{18} \mathrm{y}$, por contigüidad, a los grupos que fueron su banda sonora:

\footnotetext{
${ }^{18}$ Este homenaje es patente en el vídeo-clip realizado para este tema.
} 


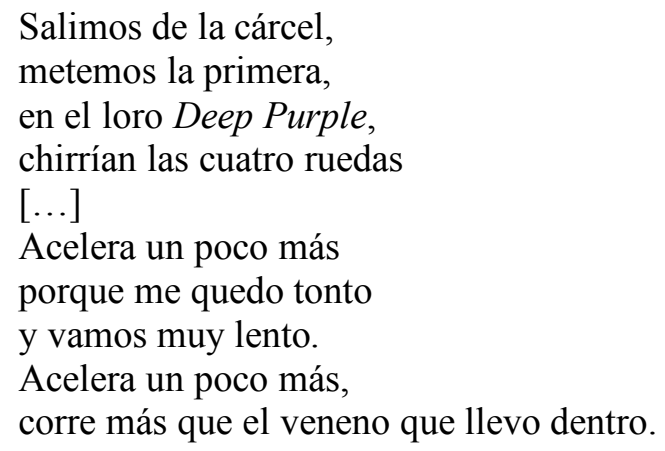

(Estopa, 1999)

Finalmente, y como se ha señalado anteriormente, Estopa se identifica repetida y abiertamente con la clase obrera; no es trivial que el propio nombre del grupo fuera elegido por los hermanos Muñoz para evocar su experiencia como obreros de una fábrica de coches en la que el encargado utilizaba la expresión jergal «dar estopa» - trabajarpara exhortar a los empleados. El tema «Pastillas de freno» (¿La calle es tuya?, 2004) es uno de los pocos ejemplos de la música española contemporánea que recoge con detalle el rigor del trabajo obrero:

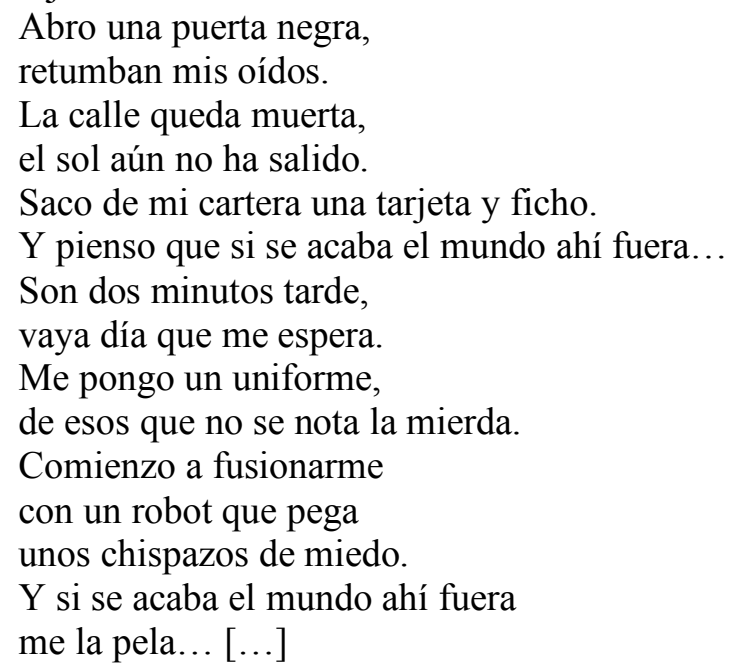

(Estopa, 2004)

Si bien se recupera ligeramente el tono festivo de la rumba catalana, la ironía de la letra de este tema es crítica, expresando el sacrificio y el hastío que produce el trabajo a destajo en condiciones de precariedad. La narrativa se centra en la cruda cotidianidad de muchos de los habitantes del barrio, trabajadores de los polígonos industriales que rodean las grandes ciudades españolas. En este sentido, resulta interesante recordar que ciertos palos tradicionales del flamenco, como la taranta o la minera, expresan con dramatismo la dureza del trabajo en la mina.

\section{CONCLUSIONES}

Si bien parcial y necesariamente limitado por razones de espacio, el análisis aquí realizado de la producción musical de Los Chichos y de Estopa sirve para ejemplificar la estética suburbana que presenta y la necesidad de reconfigurar la narrativa cultural de la España democrática, validando prácticas culturales no hegemónicas, de desarrollo urbano 
periférico. El lazo que establece Estopa con Los Chichos, tanto en la forma de sus canciones como en el contenido, es precisamente un acto político de reivindicación de la memoria cultural de la clase obrera.

La rumba suburbana de los años setenta abrió el camino a realizaciones musicales que se hacen fuertes en la escena musical de la década posterior, como el Nuevo Flamenco. Esta última tendencia, consagrada por grupos como Ketama o Pata Negra, no será representada como marginal por no poseer el carácter barrial de la rumba suburbana. Además, sus intérpretes vienen de reconocidas familias flamencas y, en general, poseen un pedigrí musical con el que no contaban los grupos surgidos en el barrio.

Como expresión musical de una determinada forma de vivir el mundo, la rumba suburbana es una práctica racializada, como racializados están los sujetos que la producen y consumen. Estos no son solo personas de la comunidad gitana, sino también los payos que conviven con ellos en el barrio, y que son denostados con términos como «payos» (por su asociación con los gitanos), «calorros», «quinquis», «macarras» o, más recientemente, «chonis», «canis» o «poligoneros». Todas estas expresiones aluden a la percepción racializada que se tiene de esos sujetos desde los valores hegemónicos de diferencia (y discriminación) social. En varios de sus temas, Estopa resignifica el término «calorro», con el cual se identifica el yo lírico. Sin duda, el más conocido de estos temas es «Tu calorro» (Estopa,1999), una composición que sintetiza lo mejor de la rumba suburbana de tema amoroso. En sus conciertos, el líder del grupo se dirige frecuentemente a la audiencia con ese mismo calificativo, reclamando así una identidad mestiza y obrera.

La recuperación de la memoria y del legado cultural de la clase obrera española es una tarea ardua y problemática porque las identidades sociales no son siempre evidentes. La reconstrucción de la memoria cultural obrera es una tarea necesaria para revelar la contribución de este colectivo al desarrollo del país durante la segunda mitad del siglo XX, así como para promover valores inclusivos.

\section{REFERENCIAS BIBLIOGRÁFICAS}

Castelló Segarra, Jorge. 2018. «Cine quinqui. La pobreza como espectáculo de masas». Filmhistoria 28 (1-2): 113-128.

Clemente, Luis. 2013. «Rock andaluz en la viña peninsular. Un cierto movimiento con aroma flamenco». En Rock around Spain. Historia, industria, escenas y medios de comunicación, eds. Kiko Mora y Eduardo Viñuela. Lleida: Edicions de la Universitad de Lleida. 139-153.

Cuesta, A. y Cuesta, M. 2009. Quinquis de los 80. Barcelona: CCCB.

Díaz-Guerra, Iñako. 2019. «Entrevista a Estopa». El Mundo, 17 de octubre. https://www.elmundo.es/papel/cultura/2019/10/17/5da71995fc6c8380068b4589. html

Domènech Sampere, Xavier. 2003. «La otra cara del milagro español. Clase obrera y movimiento obrero». Historia Contemporánea 26: 91-112.

—. 2011. «Movimiento obrero y cambio político en España (1956-1977)». En Reevaluaciones. Historias locales y miradas globales. Actas del VII congreso de Historia local de Aragón, eds. Carmen Frías et al. Zaragoza: Institución Fernando el Católico y Universidad de Zaragoza. 179-190.

Folch, Enric. 2013. «At the Crossroads of Flamenco, New Flamenco and Spanish Pop. The Case of Rumba». En Made in Spain. Studies in Popular Music, eds. Silvia Martínez y Héctor Fouce. New York: Routledge. 17-27.

Fouce, Héctor. 2002. El futuro ya está aquí. Música pop y cambio cultural en España. Madrid 1978-1985. Madrid: Universidad Complutense. [Tesis doctoral]. 
— y Fernán del Val. 2013. «Popular Music as the Discourse of Modernity in Democratic Spain». En Made in Spain. Studies in Popular Music, eds. Silvia Martínez y Héctor Fouce. New York: Routledge. 125-134.

Frith, Simon.1996. «Música e identidad». En Cuestiones de identidad cultural, comps. Stuart Hall y Paul du Gay. Buenos Aires: Amorrortu. 182-213.

Giddens, Anthony. 1984. The Constitution of Society. Outline of the Theory of Structuration. Cambridge: Polity Press.

Halbwachs, Maurice. 1994 [1925]. Les cadres sociaux de la mémoire. Paris: Albin Michel.

—.1997 [1950]. La mémoire collective. Paris: Albin Michel.

Imbert, Gérard. 2015. «Cine quinqui e imaginarios sociales. Cuerpo e identidades de género». Área abierta 15 (3): 56-67.

Jones, Owen. 2011. Chavs: the Demonization of the Working Class. Londres: Verso.

Lefebvre, Henri. 2000. La production de l'espace. Paris: Anthropos.

Lenore, Víctor. 2016. «Música en la CT: los sonidos del silencio». CT o la Cultura de la Transición. Crítica a 35 años de cultura española, coord.. G. Martínez. Barcelona: Debolsillo. 115-123.

López Castellano, Ramón. 2018. «El flamenco pop como tecnología del cambio social en España: del desarrollismo nacionalflamenquista al cuerpo biorrumbero de la Transición». Trans. Revista Transcultural de música 21-22: 1-18.

Manuel, Peter. 1989. "Andalusian, Gypsy, and Class Identity in the Contemporary Flamenco Complex». Ethnomusicology 33 (1): 47-65.

Marí, Jorge. 2009. «La Movida como debate». Arizona Journal of Hispanic Cultural Studies 13: 127-141.

Martínez, Guillem (coord.). 2016 [2012]. CT o la Cultura de la Transición. Crítica a 35 años de cultura española. Barcelona: Debolsillo.

Martínez, Silvia y Héctor Fouce. 2013. «Avoiding Stereotypes: A Critical Map of Popular Music in Spain». En Made in Spain. Studies in Popular Music, eds. Silvia Martínez y Héctor Fouce. New York: Routledge. 1-13.

- y Héctor Fouce (eds.). 2013. Made in Spain. Studies in Popular Music. New York: Routledge.

Mora, Miguel. 1999. «Los Chichos cumplen 25 años de rumba y 15 millones de discos vendidos». El País, 13 de octubre.

https://elpais.com/diario/1999/10/13/cultura/939765610 850215.html

Mora, Kiko y Viñuela, Eduardo (eds.). 2013. Rock around Spain. Historia, industria, escenas y medios de comunicación. Lleida: Edicions de la Universitat de Lleida.

Navarro López, Vicenç. 2006. El subdesarrollo social de España: causas y consecuencias. Barcelona: Anagrama.

Núñez, Faustino. 1998. Todo el flamenco. Cantes de ida y vuelta y del folclore. Tudela: Edilibro.

Ortiz Nuevo, José Luis. 1985. Pensamiento político en el cante flamenco. Antología de textos desde los orígenes a 1936. Sevilla: Editoriales Andaluzas Unidas.

Pàmies, Sergi. 2001. «En medio de Los Chichos». El País, 19 de mayo. https://elpais.com/diario/2001/05/19/catalunya/990234443 850215.html

Pérez Custodio, Diana. 2005. Paco de Lucía. La evolución del flamenco a través de sus rumbas. Cádiz: Universidad de Cádiz.

SteinGress, Gerhard. 2004. «La hibridación transcultural como clave de la formación del Nuevo Flamenco (aspectos históricos, sociológicos, analíticos y comparativos)». Revista transcultural de música 8: s/p. 
https://www.sibetrans.com/trans/articulo/198/la-hibridacion-transcultural-como-clavede-la-formacion-del-nuevo-flamenco-aspectos-historico-sociologicos-analiticos-ycomparativos

Todd, Selina. 2014. The People. The Rise and Fall of the Working Class, 1910-2010. Londres: John Murray.

Val, Fernán del, Noya, Javier y Martín Pérez-Colman, C. 2014. «¿Autonomía, sumisión o hibridación sonora? La construcción del canon estético del pop-rock español». Revista española de investigaciones sociológicas 145: 147-180.

Vilagrasa Ibarz, Joan. 1997. «Desarrollo urbano y promotores inmobiliarios en España. Una visión general». En Vivienda y promoción inmobiliaria en España, ed. Joan Vilagrasa. Lleida: Edicions de la Universitat de Lleida. 7-34.

Viñao, Antonio. 2009. «La alfabetización en España: un proceso cambiante de un mundo multiforme». EFORA 3 (1):5-19. http://campus.usal.es/ efora/efora_03/articulos_efora_03/n3_01_vinao.pdf

Whittaker, Tom. 2012. «Mobile soundscapes in the quinqui film». En Screening Songs in Hispanic and Lusophone Cinema, eds. Lisa Shaw y Rob Stone. Manchester: Manchester University Press. 98-113

—. 2020. The Spanish Quinqui film. Delinquency, Sound, Sensation. Manchester: Manchester University Press.

\section{Referencias discográficas}

Estopa. 1999. Estopa. Sony Music.

—. 2001. Destrangis. Sony Music

- 2004. ¿La calle es tuya? Sony Music.

-. 2005. Voces de ultrarumba. Sony Music.

Los Chichos. 1974. Ni más ni menos. Phillips.

-.1977. Son ilusiones. Phillips.

-.1980. Amor de compra y venta. Phillips.

-.1982. Ni tú ni yo. Phillips.

-.1985. Yo, El Vaquilla. Phillips.

—. 1988. Ojos negros. Phillips.

\section{Referencias audiovisuales}

Perros callejeros. 1977. Dir. José Antonio de la Loma. Films Zodiaco, Profilmes S.A.

Yo, El Vaquilla. 1985. Dir. José Antonio de la Loma. Golden Sun S.A., Jet Films S.A., In-Cine S.A. 